\title{
An Exploratory Investigation Into Factors Contributing to Computer-Based Testing
}

\author{
Firooz Mahmoodi, ${ }^{1,}$ and Rajab Esfandiari ${ }^{2}$ \\ ${ }^{1}$ Curriculum Studies Department of Education, Faculty of Education and Psychology, University of Tabriz, Tabriz, IR Iran \\ ${ }^{2}$ English Language Teaching, Department of English Language, Faculty of Humanities, Imam Khomeini International University, Qazvin, IR Iran \\ "Corresponding author: Firooz Mahmoodi, Curriculum Studies, Department of Education, Faculty of Education and Psychology, University of Tabriz, Tabriz, IR Iran. E-mail: \\ firoozmahmoodi@tabrizu.ac.ir
}

Received 2016 November 01; Accepted 2016 December 21.

\begin{abstract}
Background: Computer-based testing (CBT) is gaining in popularity in educational settings, and students seem more inclined to take tests delivered via computers. This study aimed at examining factors affecting CBT.

Methods: This descriptive study intended to explore factors which might affect medical computer-based testing (CBT). Accordingly, a researcher-made questionnaire (alpha $=0.86$ ) was administered to 264 conveniently selected medical students enrolled in general English language courses at Qazvin University of Medical Sciences in Spring 2016. The validity of the questionnaire was confirmed seeking experts' opinions. Data were analyzed using SPSS (version 23).

Results: The results of exploratory factor analysis showed that six factors could affect CBT. These six factors explained $55.91 \%$ of the variance. Among the factors, self-esteem accounted for the highest variance (26.34\%), while cost-effectiveness accounted for the lowest variance (4.73\%).

Conclusions: These findings suggest that CBT may motivate medical language learners, building their self-esteem and identity. Therefore, they may prefer it to pencil-and-paper tests because of the higher accuracy of CBT.
\end{abstract}

Keywords: Assessment Forms, Online Testing, Technology, Attitude

\section{Background}

Technology plays a crucial role in facilitating teaching/learning process. Thus, many more sophisticated types of technology have been developed recently. Over the past three decades, technology has made significant inroads into educational settings (1-3). Technology may affect the ways of thinking, decision making, teaching, and learning processes, curriculum development, materials production, as well as evaluation of teaching and learning (4).

The introduction of technology into curriculum development has led to a distinction between "informationage mindset" and "industrial-age mindset" (5), which implies that language learners learning in the information age may think, understand, perceive, and apply things differently from those in the industrial age. By implication, language learners send and receive information by using more sophisticated modes of technology, including the computer and the Internet. Therefore, it seems so natural that the generation belonging to this era prefers to receive and send any kind of information and messages through the Internet, preferring computers to exam sheets (6).

One of the applications of technology for educational settings is the use of technology to deliver tests to students (7). Researchers are currently using computers to develop, administer, and score tests. Students sit at their computers and take the tests. This is known as computer-based testing (CBT) (8). The results of previous research have shown that CBT results in test takers' increased self-confidence and a sense of personal identity (7). However, factors contributing to CBT among medical language learners have not been examined in the Iranian setting. In this study, we explore the factors which may affect CBT among medical language learners at Qazvin University of Medical Sciences.

Information and communications technology (ICT) has found its way into educational systems $(9,10)$. Technology has been regarded as a lever of change in educational systems. Thus, a growing increase in the use of computers for testing purposes in higher education levels has attracted the attention of educators (11). In fact, computerized testing has begun to be common and implemented in large-scale testing (12).

CBT offers a number of advantages. One of the advantages includes "flexibility in time and space, immediate scoring and feedback, and cost-effectiveness" (9). CBT also has many privileges for teachers and students. For example, teachers can grade the exam papers and post the scores immediately on line, thereby saving time. Students can study their exam sheets as a reference whenever they like and learn from them. In addition, there would be more 
transparency and accuracy, and students can also use their previous computer-based knowledge and skills during the exams $(4,13)$. CBT also plays a pivotal role in reducing greenhouse gases through cutting fewer trees for paper production, resulting in a cleaner environment (14).

The number of test methods employed in higher education levels to measure academic progress exceeds fifty, ranging from paper-and-pencil to various computer-based tests (15). Examples of shifting from paper-and-pencil tests to computer-based tests include entrance exams in postsecondary education, psychology, medicine, and computer programming (13-15). There have been many kinds of comparisons and contrasts between computer- and paperbased testing for more than two decades (16). However, they did not imply that one is preferred to the other (17).

Prior to 1992, studies on CBT concentrated on traditional outcome measures $(18,19)$. The findings from these studies revealed that reading from a computer screen was $20 \%$ to $30 \%$ slower than that from an exam sheet, accuracy was lower, and comprehension was poorer (19). The findings also revealed that using computers was more timeconsuming, language learners were more anxious when using computers and their computer literacy level was low. However, other studies have pointed to the advantages of $\mathrm{CBT}$, including richness in graphical and dynamic presentation of the test contest (20).

User characteristics were also considered of great importance. Some users get used to new methods more easily and much faster, while some others find themselves lost when encountering new situations. However, the quality of images presented to the reader can have a very imperative role in this regard. Clear presentation without flicker can provide good images (18-20).

Other studies (20-22) have concentrated on another important issue: the score equivalency. Since individual psychometric assessments are time-consuming and require much concentration and attention on behalf of test-givers and test-takers, CBT can be regarded as an acceptable alternative to the paper-based testing (13). However, switching from paper-and-pencil testing to computerized testing may change the psychometric features of the test in terms of speed and difficulty. With CBT, tests would be speeded and more difficult to answer $(23,24)$. CBT is very helpful in administrative and interpretive domains. It determines whether the test-takers understand the task $(25,26)$. Green also regards computers as something accepted and welcomed by the young and a "boon" in testing the handicapped; the deaf and near blind people can enlarge the print and the letter sizes as much as they need (26).

Post-1992 research emphasized ICT in education in different fields of teaching such as presenting the course to students (27). Due to the inclusion of ICT in education, it is required to re-consider and rethink, modify or change the traditional testing methods (28). This is considered a giant step bringing about a revolution in test methods in educational contexts $(28,29)$.

According to Bodmann and Robinson, CBT offers several advantages over traditional paper-based testing. Technology-based testing provides opportunities to measure complex forms of knowledge and reasoning, which is not possible to assess through traditional methods (30). The link between observation and interpretation through CBT makes it possible to score and interpret multiple aspects of student performance on a wide range of tasks, comparing the results against profiles that have interpretive value (31).

Recently, some studies have been conducted to evaluate the effectiveness of CBT compared to paper-and-pencil testing. The findings have shown that $\mathrm{CBT}$ is more motivating (32). A comparison was made between paper-, and computer-based L2 reading achievement tests. Alamiri also investigated the relationship between several factors such as computer familiarity, computer attitude, and testing mode preference on students' performance. The results indicated that computer familiarity and computer attitude did not have any significant effect on the overall students' performance on computer-based tests (33).

Among important factors, computer anxiety has been cited as a disadvantage, but computer familiarity and experience have been regarded as advantages (34). However, a direct association was found between increasing computer literacy and decreasing anxiety. Those students who had prior academic attainment, used e-mails and browsed on the Internet, and used computers less anxiously were more successful $(13,19,34)$. Studies have also indicated that even students with rather limited computer knowledge and skills accepted the method and preferred CBT to paper-based testing $(26,31,35)$.

On the other hand, some other studies are concerned with the major inhibitors to the adoption of educational technology (36-38). Researchers and academics sometimes face problems developing technology skills, implementing technology, and maintaining the courseware. They usually find it pressuring and time consuming (39-42). Moreover, short life cycles and constant need for being upto-date keep them busy and distract their concentration (42).

To sum up, as the above review of the literature shows, prior to 1990s, paper-based tests were preferred to computer-based tests. However, as Green noted, computers were becoming more common and more popular (26). Therefore, a move away from paper-based testing to computer-based testing has become common since mid1990s $(26,41)$. Today, large testing organizations, includ- 
ing Educational Testing Service (ETS) are administering online tests. Test of English as a foreign language the Internet based test (TOEFL iBT) is a very good example of such on-line tests. Although computer-based tests are becoming more popular, factors affecting test takers' attitudes towards these tests have not been studied yet $(17,19)$. This study, therefore, aimed to explore the factors which might affect using an online language test among medical language learners in the Iranian context.

The following research question, therefore, was formulated to explore the factors contributing to CBT:

What are the factors which may affect CBT among Iranian medical language learners?

\section{Methods}

Two hundred and sixty-four male and female undergraduate medical students at Qazvin University of Medical Sciences participated in the present study in 2016. The participants were conveniently selected from different fields of study in medicine. They were between 19 and 26 years of age, with a mean age of 23.15. The participants came from different cities of Iran and spoke different languages, including Persian, Turkish, and Kurdish. They had the experience of attending English language classes, but none of them had the experience of living in an English-speaking country. All the participants were provided with adequate information about the nature and reasons of the study, and were told in advance that the information provided by them would be kept confidential. The students were met outside of their classes in the university, and were kindly asked to cooperate with the lead researcher to complete the questionnaires. Those who agreed to fill out the questionnaires were supplied with a questionnaire and a pen. Because they were busy and did not have enough time to complete the questionnaires, they were asked to provide the lead researcher with their mobile phone number so that he would contact them to return the completed questionnaires.

Because the medical language learners' attitudes were going to be assessed towards CBT, a researcher-made questionnaire was used. The 5-point questionnaire included 27 items, and response categories ranged from strongly agree (5) to strongly disagree (1). The validity of the questionnaire was confirmed through reviewing previous studies, revising items for clarity, comprehensibility, and accuracy, and seeking experts' opinions. Experts included three language testers, three language teachers, and three content specialists in medicine. The questionnaire was piloted for reliability. The reliability of the questionnaire was computed using Cronbach's alpha, which gave the value of .86, considered a very high reliability coefficient.
One of the researchers met medical students individually out of their classes and administered the questionnaire to them to complete if they agreed to. The language learners had enough time to fill it out, and their questions about the items of the questionnaire were answered. Data collection lasted for one month. Initially, 350 medical students agreed to complete the questionnaires, so they were given the questionnaires, and they were asked to return the completed questionnaires at their convenience. However, 50 students never returned the questionnaires, and another 36 questionnaires were partially completed. Therefore, we used only 264 questionnaires for final data analysis.

After gathering the data, they were analyzed using IBM SPSS Statistics (version 23). Data reduction techniques were used for data analysis. These techniques are used to group several variables into much smaller underlying factors. Some of the variables may measure the same underlying trait, or construct. Therefore, factor analysis is best suited for reducing a large number of variables into more manageable, underlying factors. Specifically, an exploratory factor analysis was run because it allowed us to summarize the variables into a small manageable set of factors (42). We followed three steps for factor analysis of the data: computing correlation matrices, testing sampling adequacy, and reducing the variables.

\section{Results}

One hundred and thirty-five female, as well as 129 male, medical language learners in different fields of study in medicine participated in this study. The average age of the learners was 23.15 .

To answer the research question formulated in this study, the following factor analytic procedures were used. We first computed the correlation matrices. The results of Bartlett test of sphericity $(\mathrm{df}=351, \mathrm{P}=0.0001<0.05$ ) showed that the items were correlated, supporting the validity of data for factor analysis. We then tested the sampling adequacy, using Kaiser-Meyer-Olkin (KMO) Measure of sampling adequacy. The results showed that KMO was above .06, indicating that the sample size was suitable for factor analysis. The results of Bartlett test of sphericity and KMO measure of sampling adequacy are shown in Table 1.

After ensuring about the suitability of data for factor analysis, we finally used principle components analysis (PCA) to identify the factors. PCA was performed on 27 items of the questionnaire, revealing a positive relationship between the variables. Since the number of factors exceeded two, rotation was necessary to identify how the initially extracted factors differed from each other, and to provide a clear picture of the items loading on the factors. 
Table 1. Results of Sampling Adequacy Test and Validity of Factor Analysis Data

\begin{tabular}{lc}
\hline Variable & Value \\
\hline $\begin{array}{l}\text { Kaiser-Meyer-Olkin measure of sampling } \\
\text { adequacy }\end{array}$ & 0.81 \\
\hline & Bartlett's test of sphericity \\
\hline Approx. chi square & 2204.79 \\
\hline Df & 351 \\
\hline Sig. & $<0.001$ \\
\hline
\end{tabular}

Principles component analysis and varimax rotation were used to extract factors. Kaiser Criterion and scree plot were used to decide on the number of factors. As can be seen in Table 2, only six factors had Eigen values greater than 1 when Kaiser Criterion was used (43). Analysis of scree plot (Figure 1) also shows the presence of six possible factors.

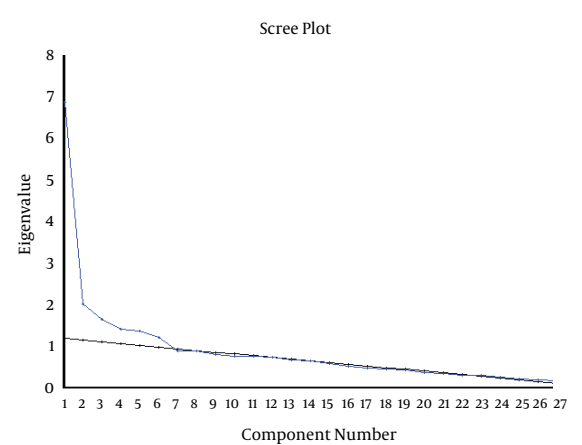

Figure 1. Scree Plot for Factors

Table 2 shows information on the positive relationship between the variables and the number of extracted factors.

Using rotation, a six-factor solution for CBT was identified. Table 2 shows these six factors whose Eigen values exceed 1 . To examine the relationship between factors and label them, loadings greater than 0.3 played an important role in labeling factors, and loadings less than 0.3 were disregarded because they were random (44). As can be seen in Table 3, all items had loadings greater than 0.3. Figure 1 also shows the presence of six possible factors for 27 items.

Factor 1 loaded highly on items 1, 2, 3, 4, and 14; factor 2 on items 7, 8, 10,11, and 26; factor 3 on items 9, 15, 21, and 25 ; factor 4 on items $16,17,18,19$, and 22 ; factor 5 on items 6 , 23 , and 24; and factor 6 on items 12,13, and 27. The variance explained by the above individual factors included $26.344 \%$ (factor 1), 7.796\% (factor 2), 6.346\% (factor 3), 5.436\% (factor 4), 5.259\% (factor 5), and $4.734 \%$ (factor 6).

These six factors accounted for 55.915 percent of the total variation, indicating that it is a useful extraction as it diminished 27 items to only six factors. Self-esteem and iden- tity were related to intrinsic factors, but cost-effectiveness was concerned with external factors. Transparency and organization, confidence and accuracy, and enhancement of computer-based knowledge and skills can be considered both intrinsic and extrinsic.

\section{Discussion and Conclusion}

This exploratory study was an attempt to identify the factors that may have an influence on CBT at Qazvin University of Medical Sciences. The results of the PCA revealed that six factors can affect CBT. These factors were predominantly intrinsic, suggesting that medical language learners would prefer CBT for their own sake. These findings are consistent with those of Jafari (45), who argued that language learners do not necessarily prefer to take CBT for external factors.

Medical language learners seem to find respect and confidence from authorities' side in taking exams in a personal cabin with a computer device dedicated specifically to each of them. This possibly would raise their self-esteem and give them a sense of possessing a personal identity. This finding is consistent with that of previous studies (32, $46,47)$. Sivin-Kachala (48) found that students studying in a technology-rich environment achieved higher marks in all subject areas, gained a positive attitude towards learning, were able to generate new ideas, and built self- confidence. The findings of other studies have also indicated that participants prefer the computerized form of the test (48-51). Likewise, Horton and Lovitt (52) and Hallfors et al. (53) found that participants favored learning information from a computer and they were more positive about computers than papers. They can also use their computer knowledge in taking a test which would be accurate, transparent, and well-organized.

On-line tests seem to be more efficient (54). Not only is automated grading of exam sheets faster, but also it is economically more beneficial than traditional grading (5459). Using computers in teaching and learning cannot be accomplished without computer-based testing, since these two are closely connected (60) to the point that even in some universities, students take their exams at their own convenient time in the exam hall $(4,7,13,48)$.

As the findings showed, CBT is cost beneficial. CBT, therefore, from a logistic point of view, can help save much more paper, lowering the costs (61). Language teachers do not need to waste a large amount of paper to write down the items on and have them printed for students. Students can have the computer-based tests at their computers at schools and take them very neatly.

Based on the findings of the study, we argue that language teachers should invest in the internal desires of lan- 
Table 2. Total Variance Explained

\begin{tabular}{|c|c|c|c|c|c|c|}
\hline \multirow[t]{2}{*}{ Component } & \multicolumn{3}{|c|}{ Initial Eigen values } & \multicolumn{3}{|c|}{ Extraction Sums of Squared Loadings } \\
\hline & Total & Variance $^{\mathbf{a}}$ & Cumulative $^{\mathrm{a}}$ & Total & Variance $^{\mathbf{a}}$ & Cumulative $^{\mathbf{a}}$ \\
\hline 1 & 6.84 & 26.34 & 26.34 & 6.84 & 26.34 & 26.34 \\
\hline 2 & 2.02 & 7.79 & 34.14 & 2.02 & 7.79 & 34.14 \\
\hline 3 & 1.65 & 6.34 & 40.48 & 1.65 & 6.34 & 40.48 \\
\hline 4 & 1.41 & 5.43 & 45.92 & 1.41 & 5.43 & 45.92 \\
\hline 5 & 1.36 & 5.25 & 51.18 & 1.36 & 5.25 & 51.18 \\
\hline 6 & 1.23 & 4.73 & 55.91 & 1.23 & 4.73 & 55.91 \\
\hline 7 & 0.99 & 4.41 & 60.32 & & & \\
\hline 8 & 0.98 & 3.80 & 64.12 & & & \\
\hline 9 & 0.91 & 3.52 & 67.64 & & & \\
\hline 10 & 0.87 & 3.35 & 71.00 & & & \\
\hline 11 & 0.78 & 3.03 & 74.03 & & & \\
\hline 12 & 0.78 & 3.01 & 77.05 & & & \\
\hline 13 & 0.68 & 2.64 & 79.70 & & & \\
\hline 14 & 0.65 & 2.50 & 82.20 & & & \\
\hline 15 & 0.59 & 2.27 & 84.48 & & & \\
\hline 16 & 0.52 & 1.03 & 85.51 & & & \\
\hline 17 & 0.48 & 1.86 & 87.37 & & & \\
\hline 18 & 0.47 & 1.81 & 89.19 & & & \\
\hline 19 & 0.45 & 1.73 & 90.92 & & & \\
\hline 20 & 0.38 & 1.46 & 92.38 & & & \\
\hline 21 & 0.34 & 1.33 & 93.71 & & & \\
\hline 22 & 0.31 & 1.22 & 94.94 & & & \\
\hline 23 & 0.31 & 1.19 & 96.13 & & & \\
\hline 24 & 0.27 & .99 & 97.13 & & & \\
\hline 25 & 0.23 & .97 & 98.10 & & & \\
\hline 26 & 0.21 & .95 & 99.06 & & & \\
\hline 27 & 0.18 & .93 & 100.00 & & & \\
\hline
\end{tabular}

guage learners to motivate them to take computerized tests more willingly, although external factors need to be considered as well.

Intrinsically motivated test takers may take on-line tests more seriously, get all the items patiently, prepare themselves for tests more willingly, and reflect on testtaking processes more carefully. Viewed from this perspective, on-line tests can offer more positive washback compared to traditional paper-based tests (62), motivating language learners to involve in course contents and course objectives. Furthermore, when language learners are comfortable with on-line tests, as the results of the study showed, their affective filter is lowered, and they are psychologically more prepared to take such tests. Therefore, tests are no longer viewed as how much they have learned, but how learning has occurred.

Language teachers should bear in mind that computerdelivered tests appeal to language learners especially the present generation of language learners who are born growing up with computers and many other sophisticated technology types. They, therefore, should supply the learn- ers with more opportunities to take tests on line (63). This may require language learners to use computer-mediated tests prepared by teachers in language classes. Quizzes, mid-term exams, and final-term exams can be given using computers.

Curriculum developers should include skills and strategies in textbooks to familiarize language learners with on-line testing. Since computer-based tests are much more recent developments, compared to traditional paper-and-pencil tests, language learners should know how to take them. Research shows that those language learners who possess computer literacy are much more successful in performance on computer-based tests (52, 64). Therefore, the barriers to using computer-based testing, including inadequate test preparation and failure to grasp the unique requirements for implementing and maintaining computer tests, should be removed. In other words, some factors such as the design, development, administration, and user characteristics must be taken into consideration when computers are going to be used for testing. 
Table 3. Rotated Component Matrix

\begin{tabular}{|c|c|c|c|c|c|c|}
\hline \multirow[t]{2}{*}{ Items } & \multicolumn{6}{|c|}{ Factors } \\
\hline & 1 & 2 & 3 & 4 & 5 & 6 \\
\hline 2. I like online testing because it is more pleasurable. & 0.79 & & & & & \\
\hline 3. I like online testing because it makes me feel involved in an academic activity. & 0.73 & & & & & \\
\hline 1. I like online testing because I enjoy working with computers. & 0.72 & & & & & \\
\hline 5. I like online testing because It connects me to the global village & 0.57 & & & & & \\
\hline 4. I like online testing because It makes me feel moving along with global trend & 0.55 & & & & & \\
\hline 14. I like online testing because it is easier to type on keyboard than writing with pen or pencil & 0.46 & & & & & \\
\hline 10. I like online testing because it is a window to the world of virtual reality & & 0.68 & & & & \\
\hline 11. I like online testing because it will provide me with the ability to start navigating on the internet & & 0.66 & & & & \\
\hline 7. I like online testing because I feel I too have a personality of my own & & 0.58 & & & & \\
\hline 8. I like online testing because It will help me to grow my individual identity & & 0.55 & & & & \\
\hline 26. I like online testing because I have a computer and privacy of my own space while taking the test & & 0.42 & & & & \\
\hline 25. I like online testing because It remains in my personal site and I can always review it & & & 0.64 & & & \\
\hline 9. I like online testing because I can establish an organized file of my exams at university & & & 0.63 & & & \\
\hline 21. I like online testing because the instructions would be given in a more transparent way & & & 0.61 & & & \\
\hline 15. I like online testing because I can later search my exam sheet on the website easily & & & 0.58 & & & \\
\hline 22. I like online testing because there would be minimum possibility of personal bias in the correction & & & & 0.74 & & \\
\hline 19. I like online testing because my exam sheet would be corrected more accurately & & & & 0.65 & & \\
\hline 17. I like online testing because I can learn from my mistakes & & & & 0.57 & & \\
\hline 16. I like online testing because I can evaluate my exam sheet and find my mistakes & & & & 0.55 & & \\
\hline 18. I like online testing because there is little possibility of cheating on my paper & & & & 0.54 & & \\
\hline 20. I like online testing because the exam sheets would be corrected in less time & & & & 0.52 & & \\
\hline 23. I like online testing because my computer based knowledge would be enhanced & & & & & 0.72 & \\
\hline 24. I like online testing because my computer based skills would be enhanced & & & & & 0.56 & \\
\hline 6. I like online testing because It would help me to keep a personal document of my exams & & & & & 0.52 & \\
\hline 13. I like online testing because less trees would be cut to produce papers & & & & & & 0.80 \\
\hline 12. I like online testing because less paper would be wasted & & & & & & 0.76 \\
\hline 27. I like online testing because of lower costs & & & & & & 0.62 \\
\hline
\end{tabular}

Table 4. Total Variance Explained ${ }^{\mathrm{a}}$

\begin{tabular}{lccc}
\hline Factors & Items & variance \\
\hline Self-esteem & $1,2,3,4,14$ & 26.34 & \multicolumn{1}{c}{ Cumulative } \\
\hline Identity & $7,8,10,11,26$ & 7.79 & 36.34 \\
\hline Transparency and organization & $9,15,21,25$ & 6.34 & 5.14 \\
\hline Confidence and accuracy & $16,17,18,19,22$ & 5.43 & 5.25 \\
\hline Enhancement of computer-based knowledge and skills & $6,23,24$ & 4.48 & 5.73 \\
\hline Cost effectiveness & $12,13,27$ & 51.18 \\
\hline
\end{tabular}

${ }^{\mathrm{a}}$ Value are expressed as number percent.

\section{Acknowledgments}

The authors wish to thank the medical language learners at Qazvin University of Medical Sciences who kindly agreed to participate in this study.

\section{Footnotes}

Authors' Contribution: Study design and concept, Firooz Mahmoodi and Rajab Esfandiari; Analysis and interpretation of data, Firooz Mahmoodi and Rajab Esfandiari; Drafting of the manuscript, Firooz Mahmoodi; Critical revision of the manuscript for important intellectual content, Rajab Esfandiari; Statistical analysis, Firooz Mahmoodi.

Conflict of interest: In this study, the authors did not receive any financial support from any institute. 


\section{References}

1. Kolderie T. How Information Technology Can Enable 21st Century Schools. ITIF. 2009.

2. Mahmoudi F, Mola S. Assessing the attainment of 21st century basic skills by engineering students of tabriz university [In persion] Majallah-i Amuzih-i Muhandisi-i Iran. 2016;18(69):19-36.

3. Esfandiari R, Sokhanvar F. Modified unified theory of acceptance and use of technology in investigating Iranian language learners' attitudes toward mobile assisted language learning (MALL). IJVLMS 2016;6(4):93-104.

4. Mathara Arachchi S, Dias K, R.S M. A comparison between evaluation of computer based testing and paper based testing for subjects in computer programming. IJSEA. 2014;5(1):57-72. doi: 10.5121/ijsea.2014.5105.

5. Frand J, Hagner PR, Bates T, Natalicio D, Smith KM, Gunderson M, et al. The information-age mindset. EDUCAUSE review. 2000;35(5).

6. Davis S, Meyer C. BLUR-the speed of change in the connected economy. British J Admim Mngm. 2000(22):20.

7. Thomas P, Price B, Paine C, Richards M. Remote electronic examinations: student experiences. British J of Edutl Tech. 2002;33(5):537-49. doi: 10.1111/1467-8535.00290.

8. Russell M, O'Brien E, Bebell D, O'Dwyer L. Students' beliefs, access, and use of computers in school and at home. Boston: MA: Boston College, Technology and Assessment Study Collaborative; 2003.

9. Deutsch T, Herrmann K, Frese T, Sandholzer H. Implementing computer-based assessment - A web-based mock examination changes attitudes. Com Edu. 2012;58(4):1068-75. doi: 10.1016/j.compedu.2011.11.013.

10. Scheuermann F, Björnsson JT. He transition to computer-based assessment. Luxembourg: Office for official publications of the european communities; 2009.

11. Sim G, Read J, Holfeild P. ; 2008. pp. 283-94.Heuristics for evaluating the usability of caa applications.

12. Higgins J, Russell M, Hoffmann T. Examining the effect of computerbased passage presentation of reading test performance. JTLA. 2005;3(4):1-36.

13. Clariana R, Wallace P. Paper-based versus computer-based assessment: key factors associated with the test mode effect. Bri J of Edutl Tech. 2002;33(5):593-602. doi:10.1111/1467-8535.00294.

14. DeRosa J. The Green PDF: Reducing Greenhouse Gas Emissions One Ream at a Time 2007. Available from: http://www.scribd.com/doc/ 60779195/The-Green-PDF-Revolution.

15. Jamil M, Tariq R, Shami P, Zakariys B. Computer-based vs paperbased examinations: Perceptions of university teachers. TOJET. 2012;11(4):371-81.

16. Cantillon P, Irish B, Sales D. Using computers for assessment in medicine. BMJ. 2004;329(7466):606-9. doi:10.1136/bmj.329.7466.606. [PubMed: 15361445].

17. Noyes JM, Garland KJ. Computer- vs. paper-based tasks: are they equivalent?. Ergonomics. 2008;51(9):1352-75. doi: 10.1080/00140130802170387. [PubMed: 18802819].

18. Dillon A. Reading from paper versus screens: A critical review of the empirical literature. Ergonomics. 1992;35(10):1297-326.

19. Buzzetto-More N, Sweat-Guy R, Elobaid M. Reading in a digital age: Ebooks are students ready for this learning object. IJELL. 2007;3(1):23950.

20. Bugbee AC. The Equivalence of Paper-and-Pencil and ComputerBased Testing. J Res computing Edu. 2014;28(3):282-99. doi: 10.1080/08886504.1996.10782166.

21. Cui JR, Chen Y, Zhang HY. Development and application of an online testing system for clinical nurses. Int J Nurs Sci. 2015;2(3):313-6. doi: 10.1016/j.ijnss.2015.07.005.

22. Mazzeo J, Harvey AL. The equivalence of scores from automated and conventional educational and psychological tests. ETS Res Rep Seri. 1988;1988(1):27. doi: 10.1002/j.2330-8516.1988.tb00277.x.
23. Denner S. Automated psychological testing: A review. Brit J Soci Clinc Psychol. 1977;16(2):175-9. doi:10.1111/j.2044-8260.1977.tb00213.x.

24. Space LG. The computer as psychometrician. Behav Res Methods Instrum Comput. 1981;13(4):595-606. doi:10.3758/bf03202072.

25. Schoenfeldt LF. Guidelines for computer-based psychological tests and interpretations. Comput Human Behav. 1989;5(1):13-21. doi: 10.1016/0747-5632(89)90020-4.

26. Green BF. 10Guidelines for Computer Testing. ; 1991.

27. Akdemir O, Oguz A. Computer-based testing: An alternative for the assessment of Turkish undergraduate students. Comput Edu. 2008;51(3):1198-204. doi:10.1016/j.compedu.2007.11.007.

28. Jimoh RG, Shittu AJK, Kawu YK. Students' perception of computer based test (CBT) for examining undergraduate chemistry courses. $J$ Em Trends Comput Info Sciences. 2012;3(2):125-34.

29. Ripley M. 22.;2008. Technology in the service of 21st century learning and assessment.

30. Bodmann SM, Robinson DH. Speed and Performance Differences among Computer-Based and Paper-Pencil Tests. J Edu Comput Res. 2004;31(1):51-60. doi: 10.2190/grqq-ytof-7lkb-f033.

31. Pommerich M. Developing computerized versions of paper-andpencil tests: Mode effects for passage-based tests. J Tech, L, Astm. 2004;2(6):n6.

32. Friedrich S, Bjornsson J. The transition to computer-based assessment new approaches to skills assessment and implications for large-scale testing. OPOCE. 2008.

33. Computer-based vs. Paper-based Testing: Does the test administration mode matter. BAAL. 2077; pp. 101-10.

34. Watson B. Key factors affecting conceptual gains from CAL materials. Brit J Eductl Tech. 2001;32(5):587-93. doi:10.1111/1467-8535.00227.

35. Zandvliet D, Farragher P. A Comparison of Computer-Administered and Written Tests. J Res Computing Educt. 2014;29(4):423-38. doi: 10.1080/08886504.1997.10782209.

36. O'Quinn L, Corry M. Factors That Deter Faculty from Participation in Distance Education. OJDLA. 2002;5(4):4.

37. Zellweger F. Faculty adoption of educational technology. EQ. 2007;30(1):66-9.

38. Schifter C. Perception differences about participating in distance education. OJDLA. 2002;5(1):1-14.

39. Buck J. Assuring Quality in Distance Education. Hig Edu Eur. 2001;26(4):599-02. doi: 10.1080/03797720220141933.

40. Cuban L. Oversold and underused: Computers in the classroom. Harvard University Press; 2009.

41. Jones KO, Kelley CA. Teaching Marketing Via the Internet: Lessons Learned and Challenges to Be Met.J MarkEduc Rev. 2015;13(1):81-9. doi: 10.1080/10528008.2003.11488817.

42. Deepa S, Seth M. An exploratory study of student perception of instructor traits in effective learning. Univ J Manag. 2014;2(1):1-8.

43. Cozzolino PJ, Blackie LE, Meyers LS. Self-related consequences of death fear and death denial. Death Stud. 2014;38(6-10):418-22. doi: 10.1080/07481187.2013.780110. [PubMed: 24666149].

44. Tabachnick BG, Fidel LS. A Practical Approach to using Multivariate Analyses, NK: Pearson. ; 2001.

45. Jafari SS. Motivated learners and their success in learning a second language. TPLS. 2013;3(10):1913. doi: 10.4304/tpls.3.10.1913-1918.

46. Russell M, Hoffmann T, Higgins J. NimbleTools. Teach Escept Child. 2009;42(2):6-12. doi: 10.1177/004005990904200201.

47. Kuikka M, Kitola M, Laakso MJ. Challenges when introducing electronic exam. Res L Tech. 2014;22(0) doi: 10.3402/rlt.v22.22817.

48. Sivin-Kachala J. Report on the Effectiveness of Technology in Schools, 1990-1997. Washington, DC: Software Publishers Association; 1998.

49. Pinsoneault TB. Equivalency of computer-assisted and paper-andpencil administered versions of the Minnesota Multiphasic Personality Inventory-2. Comput Human Behav. 1996;12(2):291-300. doi: 10.1016/0747-5632(96)00008-8.

50. Hansen WJ, Doring R, Whitlock LR. Why an examination was slower 
on-line than on paper. Int J Man-Mach Stud. 1978;10(5):507-19. doi: 10.1016/s0020-7373(78)80017-0.

51. Vispoel WP, Boo J, Bleiler T. Computerized and paper-and-pencil versions of the rosenberg self-esteem scale: A comparison of psychometric features and respondent preferences. Educ Psychol Meas. 2001;61(3):461-74. doi: 10.1177/00131640121971329.

52. Horton SV, Lovitt TC. A comparison of two methods of administering group reading inventories to diverse learners: Computer versus pencil and paper. Remedial Spec Educ. 1994;15(6):378-90. doi: 10.1177/074193259401500606.

53. Hallfors D, Khatapoush S, Kadushin C, Watson K, Saxe L. A comparison of paper vs computer-assisted self interview for school alcohol, tobacco, and other drug surveys. Eval Program Plann. 2000;23(2):14955. doi: 10.1016/s0149-7189(00)00011-2.

54. Weston TJ. Why faculty did-and did not-integrate instructional software in their undergraduate classrooms. Innov High Educ. 2005;30(2):99-115. doi:10.1007/s10755-005-5013-4

55. Brogden LM, Couros A. Contemplating the virtual campus: Pedagogical and administrative considerations. DKJB. 2002;68(3):22-30.

56. McCorkle DE, Alexander JF, Reardon J. Integrating business technology and marketing education: Enhancing the diffusion process through technology champions. J Mark Educ. 2001;23(1):16-24. doi: $10.1177 / 0273475301231003$
57. Demirci N. University students' perceptions of web-based vs. Paperbased homework in a general physics course. Online Submission. 2007;3(1):29-34.

58. Students' readiness for electronic examinations. Proceedings of the 5 th wseas international conference on education and educational technology. 2006; Tenerife. .

59. Stock SE, Davies DK, Wehmeyer ML. Internet-based multimedia tests and surveys for individuals with intellectual disabilities. SED. 2004;19(4):43-7.

60. Evers A, McCormick CM, Hawley LR, Muñiz J, Balboni G, Bartram D, et al. Testing practices and attitudes toward tests and testing: An international survey. Int J Tst. 2016:1-33. doi:10.1080/15305058.2016.1216434

61. Ling G. Does it matter whether one takes a test on an ipad or a desktop computer?. Int J Tst. 2016;16(4):352-77. doi: 10.1080/15305058.2016.1160097.

62. He L, Min S. Development and validation of a computer adaptive efl test. ; 2016.

63. Biswal PK, Sambho HP, Biswas S. A discrete event system approach to on-line testing of digital circuits with measurement limitation. ESTIJ. 2016;19(3):1473-87. doi: 10.1016/j.jestch.2016.04.005.

64. Silva RA, de Souza SRS, de Souza PSL. A systematic review on search based mutation testing. ; 2016. 